\title{
Bimodal Action of Menthol on the Transient Receptor Potential Channel TRPA1
}

\author{
Yuji Karashima, ${ }^{\star}$ Nils Damann, ${ }^{*}$ Jean Prenen, Karel Talavera, Andrei Segal, Thomas Voets, and Bernd Nilius \\ Laboratorium voor Fysiologie, Campus Gasthuisberg, Katholieke Universiteit Leuven, B-3000 Leuven, Belgium
}

TRPA1 is a calcium-permeable nonselective cation transient receptor potential (TRP) channel that functions as an excitatory ionotropic receptor in nociceptive neurons. TRPA1 is robustly activated by pungent substances in mustard oil, cinnamon, and garlic and mediates the inflammatory actions of environmental irritants and proalgesic agents. Here, we demonstrate a bimodal sensitivity of TRPA1 to menthol, a widely used cooling agent and known activator of the related cold receptor TRPM8. In whole-cell and single-channel recordings of heterologously expressed TRPA1, submicromolar to low-micromolar concentrations of menthol cause channel activation, whereas higher concentrations lead to a reversible channel block. In addition, we provide evidence for TRPA1-mediated menthol responses in mustard oil-sensitive trigeminal ganglion neurons. Our data indicate that TRPA1 is a highly sensitive menthol receptor that very likely contributes to the diverse psychophysical sensations after topical application of menthol to the skin or mucous membranes of the oral and nasal cavities.

Key words: TRP channels; trigeminal neurons; pain; chemosensation; menthol; mustard oil

\section{Introduction}

Menthol elicits a cooling sensation when topically applied to the skin or mucous membranes of the airways (Eccles, 1994), a popular effect which is used in many oral health care products, cosmetics, teas, and confectionary goods. In addition, analgesic effects of menthol are exploited in various over-the-counter pharmaceutical products (Green and McAuliffe, 2000; Galeotti et al., 2002), and some studies report that menthol also induces warmth, burning, irritating, or painful sensations (Green, 1992; Cliff and Green, 1994; Eccles, 1994; Namer et al., 2005).

At the molecular level, menthol sensation by mammalian primary neurons has been mainly ascribed to TRPM8 (McKemy et al., 2002; Peier et al., 2002), a member of the transient receptor potential (TRP) superfamily of cation channels. TRPM8 is expressed in a subset of small-diameter sensory neurons (McKemy et al., 2002; Peier et al., 2002; Abe et al., 2005), which constitute a functionally distinct population specifically dedicated to innocuous cold and menthol sensing (McKemy et al., 2002; Peier et al., 2002; Patapoutian et al., 2003; Thut et al., 2003).

Received March 2, 2007; revised July 13, 2007; accepted July 14, 2007.

This work was supported by grants from the Human Frontiers Science Program (HFSP Research Grant RGP 32/2004), the Belgian Federal Government, the Flemish Government, the Onderzoeksraad Katholieke Universiteit Leuven (Geconcerdeerde onderzoeksacties 2004/07, Fonds voor Wetenschappelijk Onderzoek G.0172.03, Interuniversity Poles of Attraction Program, Prime Minister's Office IUAP Nr.3P4/23, and Excellentiefinanciering EF/95/010), and the German Academic Exchange Service (N.D.). We declare that we have no competing financial interests. We thank $A$. Janssens for technical assistance and all members of the laboratory for helpful suggestions and criticisms. The tetracycline-inducible mouse TRPA1-expressing $\mathrm{CHO}_{\mathrm{O}}$ cell line was kindly provided by A. Patapoutian (Scripps Research Institute, La Jolla, CA). The TRPA1 knock-out mice were kindly provided by D. P. Corey (Harvard Medical School, Boston, MA).

*Y.K. and N.D. contributed equally to this work.

Correspondence should be addressed to Nils Damann, Department of Physiology, Campus Gasthuisberg, Katholieke Universiteit Leuven, Herestraat 49, B-3000 Leuven, Belgium. E-mail: nils.damann@med.kuleuven.be. DOI:10.1523/JNEUROSCI.2221-07.2007

Copyright $\odot 2007$ Society for Neuroscience $\quad$ 0270-6474/07/279874-11\$15.00/0
However, the multiple and ambiguous psychophysical effects of menthol cannot be explained on the basis of a single molecular target and implicate involvement of receptor proteins different from TRPM8. For example, TRPM8 does not colocalize with markers of pain fibers like calcitonin-gene-related peptide (CGRP), TRPV1, or isolectin B4 (Peier et al., 2002; Abe et al., 2005), and therefore the painful effects of menthol are unlikely to be mediated by TRPM8. Recently, two independent working groups identified menthol-sensing neurons in TRPM8-null mice (Colburn et al., 2007; Dhaka et al., 2007), substantiating the hypothesis of various molecular sensors for menthol.

TRPA1 (formerly ANKTM1) (Story et al., 2003) is activated by pungent compounds from mustard oil (allyl-isothiocyanate; MO), cinnamon (cinnamaldehyde), and garlic (allicin) (Bandell et al., 2004; Bautista et al., 2005) and is expressed in a subset of polymodal nociceptors that lack TRPM8 (Story et al., 2003; Kobayashi et al., 2005). Studies showing that inflammatory mediators like bradykinin and cannabinoids activate TRPA1 (Bandell et al., 2004; Jordt et al., 2004; Nagata et al., 2005; Obata et al., 2005), and recent investigations in TRPA1-deficient mice (Bautista et al., 2006; Kwan et al., 2006) suggest a role in chemosensation and inflammatory pain. Initially, TRPA1 was reported to be unresponsive to menthol (Story et al., 2003). In contrast, a recent study demonstrated that menthol inhibits TRPA1 currents stimulated by cold or cinnamaldehyde (Macpherson et al., 2006). However, there are no conclusive electrophysiological data on the effects of menthol on the basal properties of TRPA1.

In this study, we identified a bimodal modulation of TRPA1 gating by menthol: submicromolar to low-micromolar concentrations of menthol cause robust channel activation, whereas higher concentrations lead to a reversible channel block. Furthermore, we show that TRPA1-null mice exhibit less mentholresponding neurons, suggesting that TRPA1 senses menthol in 
vivo. In concert with the well documented sensitivity of TRPM8 for menthol, our findings provide a molecular model for the ambivalent cool-pain sensation of topical menthol.

\section{Materials and Methods}

$\mathrm{CHO}$ cell culture. We used a tetracycline-regulated system for inducible expression of TRPA 1 in CHO cells. To induce expression of TRPA1, 0.5 $\mu \mathrm{g} / \mathrm{ml}$ tetracycline was added to the culture medium, and cells were used 5-24 $\mathrm{h}$ after induction.

Electrophysiology. For electrophysiological recordings in the whole-cell mode of the patch-clamp technique, $\mathrm{CHO}$ cells were maintained in an extracellular recording solution containing (in $\mathrm{mM}$ ) $150 \mathrm{NaCl}, 5 \mathrm{CsCl}, 5$ $\mathrm{CaCl}_{2}, 10$ glucose, and 10 HEPES, buffered at $\mathrm{pH} 7.4$ with $\mathrm{NaOH}$. The intracellular standard pipette solution contained (in $\mathrm{mm}$ ) $150 \mathrm{NaCl}, 5$ $\mathrm{CsCl}, 1$ EDTA, and 10 HEPES, buffered at $\mathrm{pH} 7.2$ with $\mathrm{NaOH}$. For recordings in the cell-attached patch-clamp configuration, $\mathrm{NaCl}$ in the extracellular solution was replaced by $\mathrm{KCl}$ to null the cellular membrane potential, and $\mathrm{CsCl}$ was not added. The pipette solution for cell-attached recordings contained (in $\mathrm{mm}$ ) $150 \mathrm{NaCl}, 5 \mathrm{CaCl}_{2}, 10$ glucose, and 10 HEPES, buffered at $\mathrm{pH} 7.4$ with $\mathrm{NaOH}$. Agonists were added from stock solutions (see below, Reagents) to the extracellular recording solution. Patch-clamp electrodes were pulled from Vitrex capillary tubes (Modulohm, Herlev, Denmark) on a DMZ-Universal puller (Zeitz Instruments, Augsburg, Germany). When filled with pipette solution, they showed a $\mathrm{DC}$ resistance between 3 and $5 \mathrm{M} \Omega$. An Ag- $\mathrm{AgCl}$ wire was used as reference electrode. $\mathrm{Ag}-\mathrm{AgCl}$ electrodes of sintered pellets (IVM Systems, Healdsburg, CA) were used to avoid contamination of the bath and pipette solutions. Membrane currents were recorded using an EPC-7 patch-clamp amplifier (List Electronic, Lambrecht/Pfalz, Germany). For control of voltage-clamp protocols and data acquisition, we used the pCLAMP 9 software (Molecular Devices, Foster City, CA) run on an IBM-compatible PC, which was connected to the amplifier via a TL-1 DMA interface (Molecular Devices). For whole-cell analysis, data were recorded at $8 \mathrm{kHz}$ and filtered at $1 \mathrm{kHz}$ with pCLAMP 9 software. The cell capacitance and series resistance were assessed using the analog compensation circuit of the EPC-7 amplifier. Generally, between 50 and $80 \%$ of the series resistance was electronically compensated to minimize voltage errors. Experiments were performed at room temperature $\left(20-25^{\circ} \mathrm{C}\right)$. Single-channel analyses in the cell-attached configuration were recorded at $10 \mathrm{kHz}$ and filtered at $3 \mathrm{kHz}$.

Animals. The study was conducted using 14- to 21-d-old C67BL/6 wild-type (WT) and TRPA1 knock-out (KO) mice (Kwan et al., 2006). The animals were caged, with water and commercial food ad libitum. All animal experiments were performed in accordance with the European Union Community Council guidelines.

Primary culture of trigeminal sensory neurons. The primary cell culture of trigeminal neurons has been described previously (Damann et al., 2006) and was only slightly altered. Young mice [postnatal day 14 (P14)$\mathrm{P} 21$ ] were decapitated, and the trigeminal ganglia were excised under a microscope. The ganglia were washed in PBS (Invitrogen, Carlsbad, CA) and collected in cold Leibowitz medium (L15; Invitrogen). Ganglia were cut into small pieces and incubated $\left(37^{\circ} \mathrm{C} ; 95 \%\right.$ air and $\left.5 \% \mathrm{CO}_{2}\right)$ for 45 min in warm DMEM containing $0.025 \%$ collagenase (type IA; SigmaAldrich, St. Louis, MO).

Tissue was gently triturated with a fire-polished glass pipette, and the suspension was centrifuged at $200 \times g$ for $8 \mathrm{~min}$. The obtained pellet was resuspended in culture medium with the following composition: DMEM/F-12 (1:1) with Glutamax (Invitrogen) supplemented with 10\% fetal calf serum (Invitrogen) and $100 \mu \mathrm{g} / \mathrm{ml}$ penicillin/streptomycin.

For calcium imaging experiments cells were plated on glass coverslips covered with poly-L-lysine (Sigma-Aldrich) $(0.01 \%)$ that were placed into 12-well dishes (Greiner Bio-One, Kremsmuenster, Austria). Cells were kept in a humidified atmosphere $\left(37^{\circ} \mathrm{C} ; 5 \% \mathrm{CO}_{2}\right)$. One hour after plating, $2 \mathrm{ml}$ of culture medium was added to each dish. Neurons were grown for 12-24 $\mathrm{h}$ before being used.

Note that trigeminal neurons were cultured in the absence of NGF and maintained for the shortest period possible, because long-term maintenance of neurons in culture (several days to weeks) and presence of NGF in the culture medium influences expression of TRPA1 and TRPV1 (Winston et al., 2001; Obata et al., 2005).

$\left[\mathrm{Ca}^{2+}\right]_{i}$ measurement. $\left[\mathrm{Ca}^{2+}\right]_{\mathrm{i}}$ was measured with an imaging system consisting of a charge-coupled device camera (Roper Scientific, Ottobrunn, Germany) connected to an Axiovert 200M inverted microscope (Zeiss, Thornwood, NY). The camera was controlled by the Metafluor (version 4.65; Universal Imaging, Downingtown, PA) software running on a PC with a Pentium III processor. Cells were loaded with fura-2 AM by incubation for $20 \mathrm{~min}$ at $37^{\circ} \mathrm{C}$ in a standard extracellular solution containing $2 \mu \mathrm{M}$ fura- $2 \mathrm{AM}$. For measurements, the standard extracellular solution was used. Agonists were added from stock solutions (see below, Reagents) to the extracellular recording solution. At the end of each measurement, a $45 \mathrm{~mm} \mathrm{KCl-containing} \mathrm{extracellular} \mathrm{recording} \mathrm{so-}$ lution was used to depolarize cells and to identify neurons by calcium influx. In $\left[\mathrm{Ca}^{2+}\right]_{\mathrm{e}}$-free conditions, $\mathrm{CaCl}_{2}$ was replaced by $1 \mathrm{~mm}$ EGTA. For $\left[\mathrm{Ca}^{2+}\right]_{\mathrm{i}}$ measurements, fluorescence was measured during excitation at 350 and $380 \mathrm{~nm}$. After correction for the individual background fluorescence signals, the ratio of the fluorescence at both excitation wavelengths $\left(F_{350} / F_{380}\right)$ was monitored.

Reagents. (-)-Menthol, (+)-menthol, (-)-neomenthol, (+)neomenthol, (-)-menthyl chloride, capsaicin, and mustard oil (allyl isothiocyanate) were purchased from Sigma-Aldrich. DL-Menthol, which is a racemic mixture of $(-)$-menthol and $(+)$-menthol, was from Merck (Whitehouse Station, NJ). For preparing stock solutions, agonists were dissolved in ethanol $[(-)$-menthol, $(+)$-menthol, DLmenthol, (+)-neomenthol, (-)-neomenthol, and thymol] or DMSO (MO and (-)-menthyl chloride). Agonists were added from these stock solutions to the extracellular recording solution. The final ethanol concentration in menthol and derivates containing recording solution was $<0.1 \%$. Unless mentioned otherwise, DL-menthol was used for the measurements.

Data analysis. Electrophysiological measurement data were analyzed using the WinASCD software package (Guy Droogmans, Katholieke Universiteit Leuven, Leuven, Belgium; ftp://ftp.cc.kuleuven.ac.be/pub/ droogmans/winascd.zip). Statistical analysis and graphical presentations were performed using the Origin version 7.0 software (OriginLab, Northampton, MA). Significance was tested with ANOVA and Student's unpaired $t$ test. All data are presented as the mean \pm SEM.

\section{Results}

\section{Bimodal modulation of TRPA1 by menthol}

We performed whole-cell patch-clamp recordings in $\mathrm{CHO}$ cells expressing the mouse isoform of TRPA1. Consistent with previous reports, repetitive application of a voltage ramp from -150 to $+150 \mathrm{mV}$ from a holding potential of $0 \mathrm{mV}$ elicited sizable TRPA1 currents, indicative of constitutively open TRPA1 channels (Xu et al., 2006; Hill and Schaefer, 2007). Extracellular application of $1 \mathrm{~mm}$ menthol, which has been reported to inhibit cold- or cinnamaldehyde-activated TRPA1 currents (Macpherson et al., 2006), induced a fast inhibition of both outward and inward currents (Fig. $1 A, B$ ). Repeated application of $1 \mathrm{~mm}$ menthol caused similar inhibitory effects on TRPA1. Strikingly, washout of $1 \mathrm{~mm}$ menthol consistently induced a rapid increase of TRPA1 currents (off response) followed by a slow recovery. This result suggested that lower concentrations of menthol might have an agonistic effect on TRPA1. Indeed, $30 \mu \mathrm{M}$ menthol induced a rapid activation of both outward and inward currents, which was followed by an additional but transient current increase after washout (Fig. 1C,D). Even at $1 \mu \mathrm{M}$, menthol caused clear activation of inward and outward currents, but at this concentration a transient current increase after washout could no longer be observed. In comparison, the well known cold and menthol receptor TRPM8 does not show any measurable response at concentrations $<5 \mu \mathrm{M}$ (McKemy et al., 2002; Voets et al., 2007). Menthol stimulation of TRPA1 currents could be repeated several times in the same cell with no or moderate run-down (Fig. 
$1 A, C, E)$. In contrast, activation of TRPA1 by $\mathrm{MO}$ in the same expression system induces pronounced desensitization, such that a second MO application evokes very little $(<10 \% ; n=12)$ current response (data not shown).

Recently, two groups reported that TRPA1 is directly activated by intracellular $\mathrm{Ca}^{2+}$, and it was proposed that cold activation of TRPA1 is secondary to coldinduced release of $\mathrm{Ca}^{2+}$ from intracellular stores (Doerner et al., 2007; Zurborg et al., 2007). Notably, we found that in the complete absence of intracellular and extracellular $\mathrm{Ca}^{2+}$, menthol could still activate TRPA1 (data not shown), indicating that $\mathrm{Ca}^{2+}$ is not essential for the mode of channel modulation.

\section{Effects of menthol on the gating properties of TRPA1}

To investigate the mechanism of menthol action on TRPA1 gating in more detail, we used a voltage step protocol consisting of $300 \mathrm{~ms}$ voltage steps to test potentials ranging from -150 to $+100 \mathrm{mV}$ followed by an invariant step to $-150 \mathrm{mV}$ (Fig. 2A). This approach allows analysis of the effects of menthol on the steady-state currents (from the current at the end of the $300 \mathrm{~ms}$ test pulse) (Fig. $2 B, C$ ) and on the voltage dependence of channel activation (from tail currents (Fig. 2D).

In control conditions, the current traces displayed time-dependent activation at positive and deactivation at negative potentials (Fig. 2A), and at steadystate the $I-V$ curve showed an outward rectification pattern (Fig. $2 \mathrm{~B}$ ). The amplitude of the deactivating tail current increased with depolarization (Fig. 2D), but, similar to other voltage-gated TRP channels (Nilius et al., 2005), the voltage dependence was relatively weak, and tail current amplitudes did not saturate in the tested voltage range. Moreover, in line with previous studies, we observed variable channel inactivation at strongly depolarized voltages (Macpherson et al., 2007). Therefore, we limited our tail current analysis to voltages less than or equal to $+100 \mathrm{mV}$, as the amplitude of inward tail currents after stronger depolarization was clearly influenced by the time course of recovery from inactivation.

Application of $10 \mu \mathrm{M}$ menthol induced an increase in steadystate currents at all voltages (Fig. $2 A-C$ ) and a shift of the voltage dependence of the tail current amplitude to more negative potentials (Fig. 2D). Increasing the menthol concentration to $100 \mu \mathrm{M}$ caused a further strong increase of the inward currents, whereas outward currents decreased slightly (Fig. 2A-C). At the same time, the voltage dependence of the tail current amplitude was shifted to negative potentials, whereas the maximal tail current amplitude is significantly reduced compared with the control condition (Fig. 2D). Application of menthol at $1 \mathrm{~mm}$ produced a
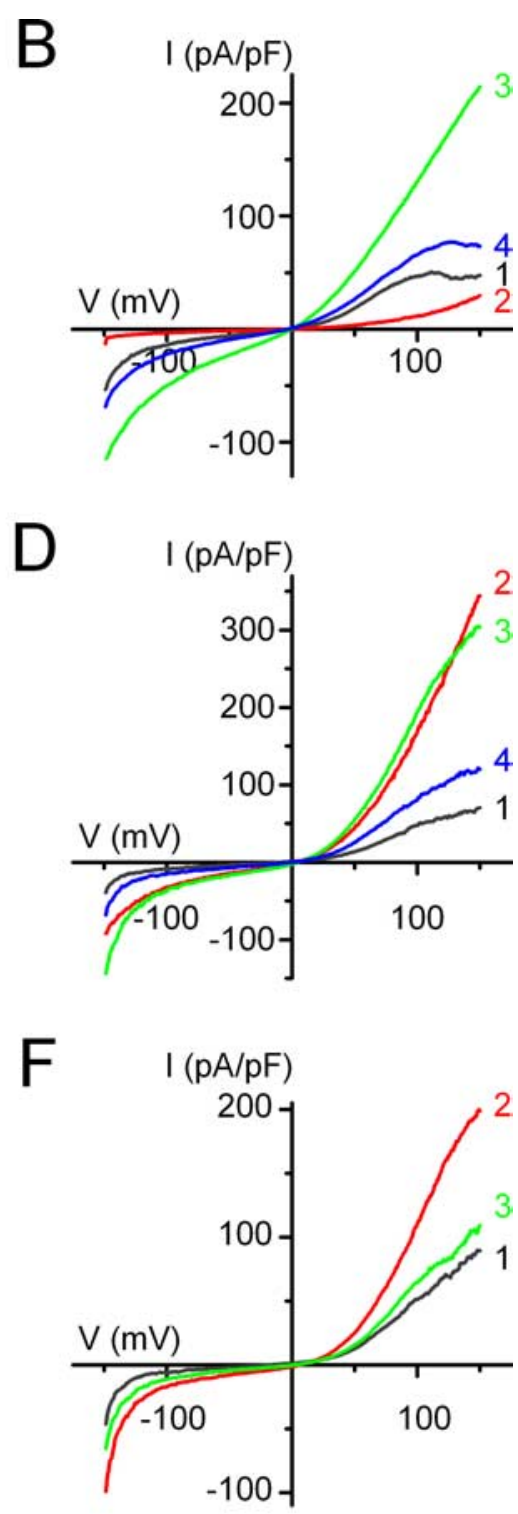

Figure 1. Bimodal modulation of TRPA1 by menthol. $\boldsymbol{A}, \boldsymbol{C}, \boldsymbol{E}$, Representative time course of the whole-cell currents at -80 (bottom trace) and $+80 \mathrm{mV}$ (top trace) during voltage ramps, elicited by $1 \mathrm{~mm}(\boldsymbol{A}), 30 \mu \mathrm{M}(\boldsymbol{C})$, and $1 \mu \mathrm{m}(\boldsymbol{E})$ menthol. A $500 \mathrm{~ms}$ voltage ramp protocol from -150 to $+150 \mathrm{mV}$ from a holding of $0 \mathrm{mV}$ was applied every 2 s. $\boldsymbol{B}, \boldsymbol{D}, \boldsymbol{F}$, Current-voltage $(I-V)$ relationships obtained at the times indicated in $\boldsymbol{A}, \boldsymbol{C}$, and $\boldsymbol{E}$, respectively.

decrease in current amplitude at all potentials (Fig. $2 A-C$ ), a complete loss of rectification in the $I-V$ curve (Fig. $2 B$ ), and small, voltage-independent tail currents (Fig. 2D).

To quantify this dual effect of menthol, we used a simple model. For the menthol-induced block of the maximal whole-cell conductance $\left(G_{\max }\right)$, we assumed a Hill-type dose dependence, according to the following equation:

$$
G_{\max }=\frac{G_{\mathrm{max}, \text { control }}}{1+\left(\frac{M}{\mathrm{IC}_{50}}\right)^{n_{\mathrm{hl}}}}
$$

where $G_{\text {max,control }}$ represents the maximal whole-cell conductance in the absence of menthol, $M$ represents the menthol concentration, $\mathrm{IC}_{50}$ represents the concentration for half-maximal inhibition, and $n_{\mathrm{h} 1}$ represents the corresponding Hill coefficient. In addition, we assumed a Boltzmann-type voltage dependence 


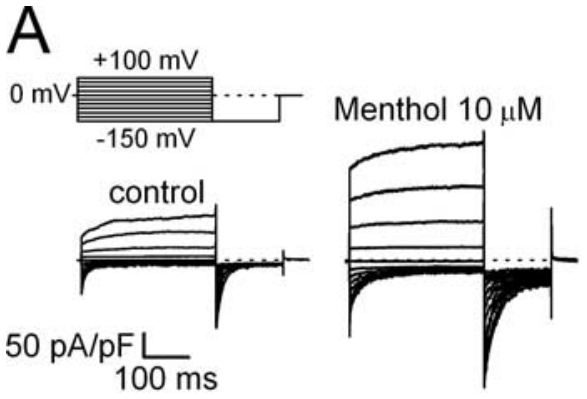

Menthol $100 \mu \mathrm{M}$
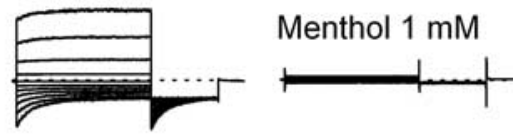

B
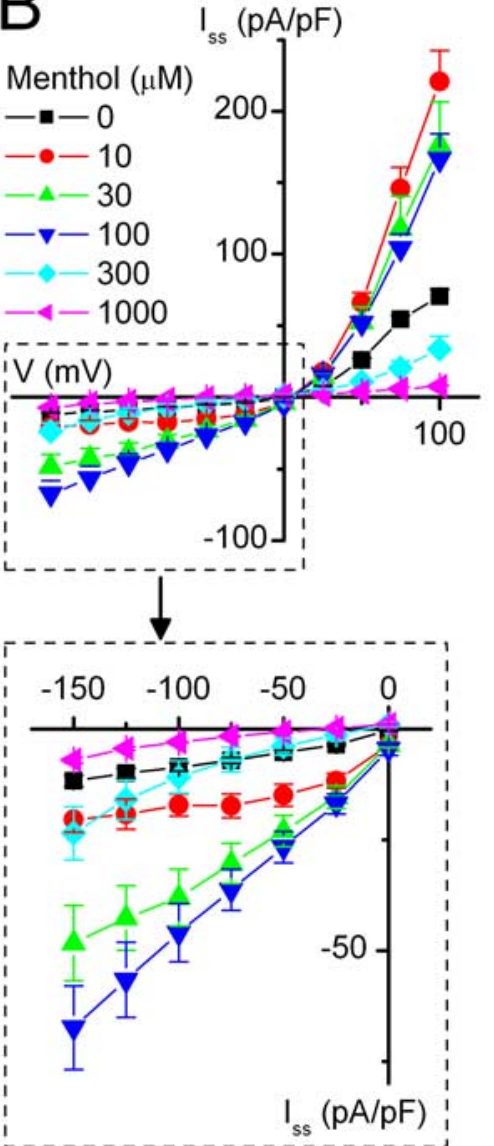

C

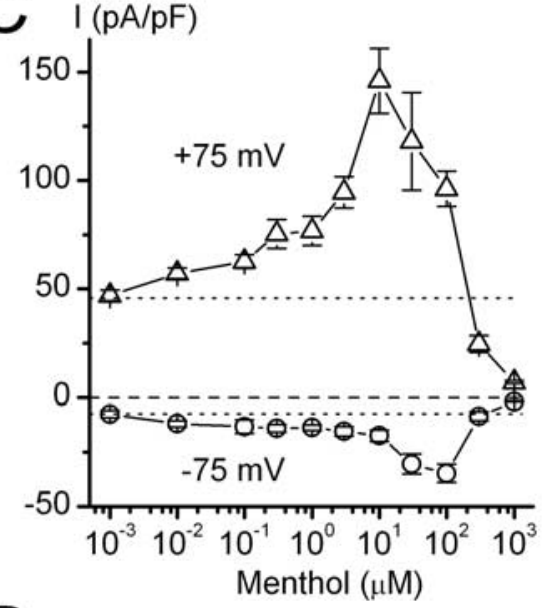

D

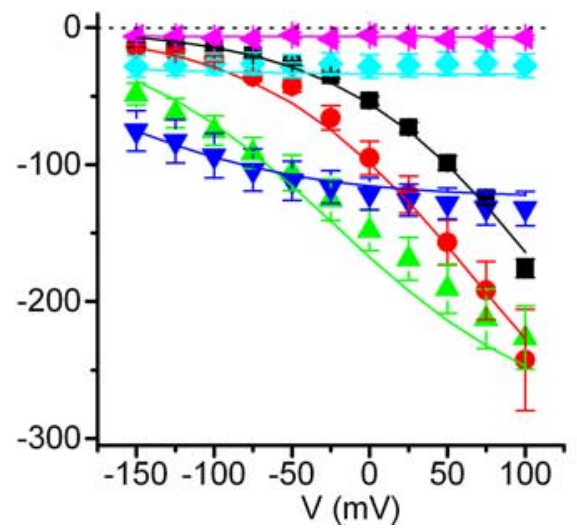

Figure 2. Effects of menthol on the gating properties of TRPA1. $\boldsymbol{A}$, Representative whole-cell TRPA1 currents in response to the indicated voltage protocol under control conditions and during application of 10 and $100 \mu \mathrm{m}$ and $1 \mathrm{~mm}$ menthol. $\boldsymbol{B}, I-V$ relationships obtained at the end of the 300 ms voltage steps shown in $\boldsymbol{A}$. C, Dose-response relationships of menthol on TRPA1 at the indicated voltages. Dotted lines indicate constitutive currents before menthol application. $\boldsymbol{D}$, Tail currents at $-150 \mathrm{mV}$ in control and during application of the different concentrations of menthol $(n=4-7)$. Continuous lines represent a global fit of the data using Equation 4. Error bars indicate SEM. Is Steady-state current.

of probability of channel activation $\left(P_{\text {act }}\right)$, according to the following equation:

$$
P_{\text {act }}=\frac{1}{1+\exp \left(\frac{-\left(\mathrm{V}-\mathrm{V}_{1 / 2}\right)}{S}\right)},
$$

where $s$ represents the slope factor, and $V_{1 / 2}$ represents the voltage for half-maximal activation, which is dependent on menthol according to the following equation:

$$
V_{1 / 2}=\frac{V_{1 / 2, \mathrm{con}}-V_{1 / 2, \mathrm{men}}}{1+\left(\frac{M}{\mathrm{EC}_{50}}\right)^{n \mathrm{n} 2}}+V_{1 / 2, \mathrm{men}},
$$

where $V_{1 / 2 \text {,con }}$ and $V_{1 / 2 \text {,men }}$ represent $V_{1 / 2}$ in the absence of menthol and at saturating menthol, respectively, $\mathrm{EC}_{50}$ represents the concentration for half-maximal effect, and $n_{\mathrm{h} 2}$ represents the corresponding Hill coefficient.

Combining Equations 1-3 yields the following expression for the tail currents:

$$
I_{\text {tail }}=V_{\text {tail }} \times G_{\text {max }} \times P_{\text {act }},
$$

where $V_{\text {tail }}$ represents the tail current voltage $(-150 \mathrm{mV})$. A global fit of this model to the tail currents at different menthol concentrations is shown in Figure 2D. For the block of the whole-cell conductance, we obtained an $\mathrm{IC}_{50}$ value of $56 \pm 8 \mu \mathrm{M}$ $\left(n_{\mathrm{h} 1}=1.42 \pm 0.09\right)$, which is very similar to the recently published value for menthol inhibition of cinnamaldehydeactivated TRPA1 currents $(68 \mu \mathrm{M})$ (Macpherson et al., 2006). For the effect of menthol on channel activation, we obtained an $\mathrm{EC}_{50}$ value of $95 \pm 15 \mu \mathrm{M}\left(n_{\mathrm{h} 2}=\right.$ $1.08 \pm 0.09)$. Menthol causes a drastic shift of the midpoint of the activation curve, as parameterized by the values for $V_{1 / 2 \text {,con }}$ and $V_{1 / 2, \text { men }}$ of $+121 \pm 15$ and $-285 \pm 88$ $\mathrm{mV}$, respectively. Note that the value for $\mathrm{V}_{1 / 2 \text {,con }}$ is very similar to what was recently published by another group $(155 \pm 25$ $\mathrm{mV}$ ) (Zurborg et al., 2007). The very negative $V_{1 / 2 \text {,men }}$ value implies that at high menthol concentrations, TRPA1 becomes voltage independent in the broad physiological voltage range, fully in line with our experimental observations showing linear $I-V$ curves under these conditions (Fig. $2 B, D)$.

\section{Effect of menthol isomers, menthyl chloride, and thymol on TRPA1}

The above-described experiments were performed using DL-menthol, which is a racemic mixture of the $(-)$ and $(+)$ stereoisomers of menthol. To investigate the stereospecificity of TRPA1 activation, we tested several different menthol stereoisomers and structurally related compounds (Fig. $3 A$ ). We found that (-)-menthol, which is the major menthol isomer in the mint plant, is the most potent in activating TRPA1, and obtained a potency order of $(-)$-menthol $\geq(+)$-menthol $>(-)$-neomenthol $\geq(+)$-neomenthol (Fig. 3A-C). Menthyl chloride also activated TRPA1, indicating that the alcohol moiety of menthol is not crucial for its activating effect on TRPA1. However, because of its low solubility we could not check whether menthyl chloride also blocked TRPA1 at higher concentrations $>100 \mu \mathrm{M}$ (Fig. 
$3 A, C)$. Thymol, a natural compound present in thyme and known activator of TRPV3 and TRPM8 (Xu et al., 2006; VogtEisele et al., 2007), is also structurally related to menthol (Fig. 3A). Interestingly, we found that thymol also activated TRPA1 at low micromolar concentrations while acting as a blocker at higher concentrations. Note that thymol was significantly more potent in activating inward TRPA1 currents than menthol (Fig. 3D).

\section{Effect of menthol on single TRPA1 channels}

Next, we analyzed the menthol modulation of TRPA1 at the single-channel level in cell-attached patches during repetitive $250 \mathrm{~ms}$ voltage steps to +80 and $-80 \mathrm{mV}$ (Fig. 4). In the absence of menthol, we measured constitutive TRPA1 singlechannel activity (Fig. 4A,B) with average open-channel current amplitudes of $-5.3 \pm 0.5$ and $7.5 \pm 0.4 \mathrm{pA}$ at -80 and $+80 \mathrm{mV}$, respectively (Fig. 4C). Notably, TRPA1 channel activity was characterized by periods of burst-like channel activity interspaced by long intermediate periods without channel openings (Fig. $4 \mathrm{~A}$ ), including a high proportion of null traces $(41 \pm 9 \%$ at $+80 \mathrm{mV}$ and $60 \pm 15 \%$ at $-80 \mathrm{mV} ; n=$ 3) (Fig. 5A). Moreover, consistent with previous reports and our whole-cell data, we observed time-dependent inactivation at +80 $\mathrm{mV}$ (Fig. 4A, $B$ ).

We defined bursts of single-channel openings as groups of channel openings separated by closed periods $>10 \mathrm{~ms}$ and determined the burst probability $\left(P_{\text {burst }}\right)$ in patches with only a single TRPA1 channel by dividing the periods of burst activity by the total recording time. Using this approach, we determined that in control conditions $P_{\text {burst }}$ equaled $0.11 \pm 0.04$ at $+80 \mathrm{mV}$ and $0.06 \pm 0.04$ at $-80 \mathrm{mV}(n=5)$ (Fig. $5 B)$.

Adding menthol to the bath at concentrations ranging from 10 to $300 \mu \mathrm{M}$ led to a clear increase in burst activity, as evidenced by a decrease in the proportion of null traces (Fig. 5A) and a significant increase in $P_{\text {burst }}$ (Fig. $5 B$ ) at both positive and negative voltages. In addition, however, menthol provoked a flickering channel block, leading to a substantial reduction of the ensemble average current at 100 and $300 \mu \mathrm{M}$ (Fig. 4A,B) and a skewing of the amplitude histograms toward the closed channel amplitude (Fig. 4C). At $1 \mathrm{~mm}$ menthol, the blocking effect of menthol became so dominant that channel openings could no longer be detected (Fig. $4 A-C$ ). Note that a similar dual effect of menthol was also observed during steady-state recordings at a fixed voltage (see supplemental Fig. S1, available at www.jneurosci.org as supplemental material).

To quantify the rapid menthol-induced channel block, we compared the open dwell times at $+80 \mathrm{mV}$ in control conditions and after addition of $100 \mu \mathrm{M}$ menthol. In the absence of menthol, open dwell-time histograms were fitted with the sum of two exponential functions, with values for $\tau_{\text {fast }}$ and $\tau_{\text {slow }}$ of $1.0 \pm 0.2$ and $6.4 \pm 0.9 \mathrm{~ms}(n=4)$, respectively, and relative amplitudes of $82 \pm 6 \%\left(A_{\text {fast }}\right)$ and $18 \pm 6 \%\left(A_{\text {slow }}\right)$ (Fig. $\left.5 C, D\right)$. After addition of $100 \mu \mathrm{M}$ menthol, open dwell times were significantly reduced, and the dwell-time histograms were well fitted with a single exponential function with $\tau=0.66 \pm 0.06 \mathrm{~ms}(n=4)$.
Together, these data show that menthol has two independent effects on TRPA1 single channels. First, menthol forces the channel to operate in the burst mode and dramatically shifts the voltage dependence of activation toward negative values, which leads to an overall increase of TRPA1 current at lower menthol concentrations. Second, menthol induces a rapid channel block, as evidenced by significantly reduced open times during periods of burst activity. This blocking effect becomes predominant at high micromolar concentrations and eventually fully shuts the channel off at a concentration of $1 \mathrm{~mm}$. Interestingly, similar to what we observed in whole-cell recordings (Fig. $1 A$ ), washout of $1 \mathrm{~mm}$ menthol resulted in transient overshoot of single-channel activity (Fig. $4 A$ ), as evidenced by an increased ensemble average current (Fig. $4 B)$, increased $P_{\text {burst }}(0.25 \pm 0.06$ at $+80 \mathrm{mV}$ and $0.37 \pm$ 0.08 at $-80 \mathrm{mV}$ ) (Fig. $5 B$ ), and low proportion of null traces (Fig. $5 A$ ). A possible explanation of this phenomenon is that the two distinct actions of menthol have different kinetics of washout, such that the blocking effect reverses much faster than the activating effect.

\section{Menthol activates MO-sensitive primary sensory neurons}

Our data in TRPA1-expressing CHO cells strongly suggest that sensory neurons express two distinct excitatory ionotropic receptors for menthol: TRPM8 and TRPA1. To assess the contribution of TRPA 1 and TRPM8 to the menthol sensitivity of native cells, we performed calcium imaging experiments on murine trigeminal neurons in primary cell culture.

Previous reports have demonstrated TRPA1 expression and sensitivity for $\mathrm{MO}$ in a subpopulation of sensory neurons from dorsal root and trigeminal ganglia (Bandell et al., 2004; Jordt et al., 2004). In our experiments, 233 of a total of 608 neurons (38.3\%) responded to $100 \mu \mathrm{M} \mathrm{MO}$. We questioned whether menthol concentrations that produced robust TRPA1 receptor activation in $\mathrm{CHO}$ cells would stimulate these sensory neurons, and found that $38.1 \%(30 / 83)$ of $\mathrm{MO}$-sensitive neurons were also activated by $30 \mu \mathrm{M}$ menthol (Fig. $6 A, C$ ). In comparison, in the 


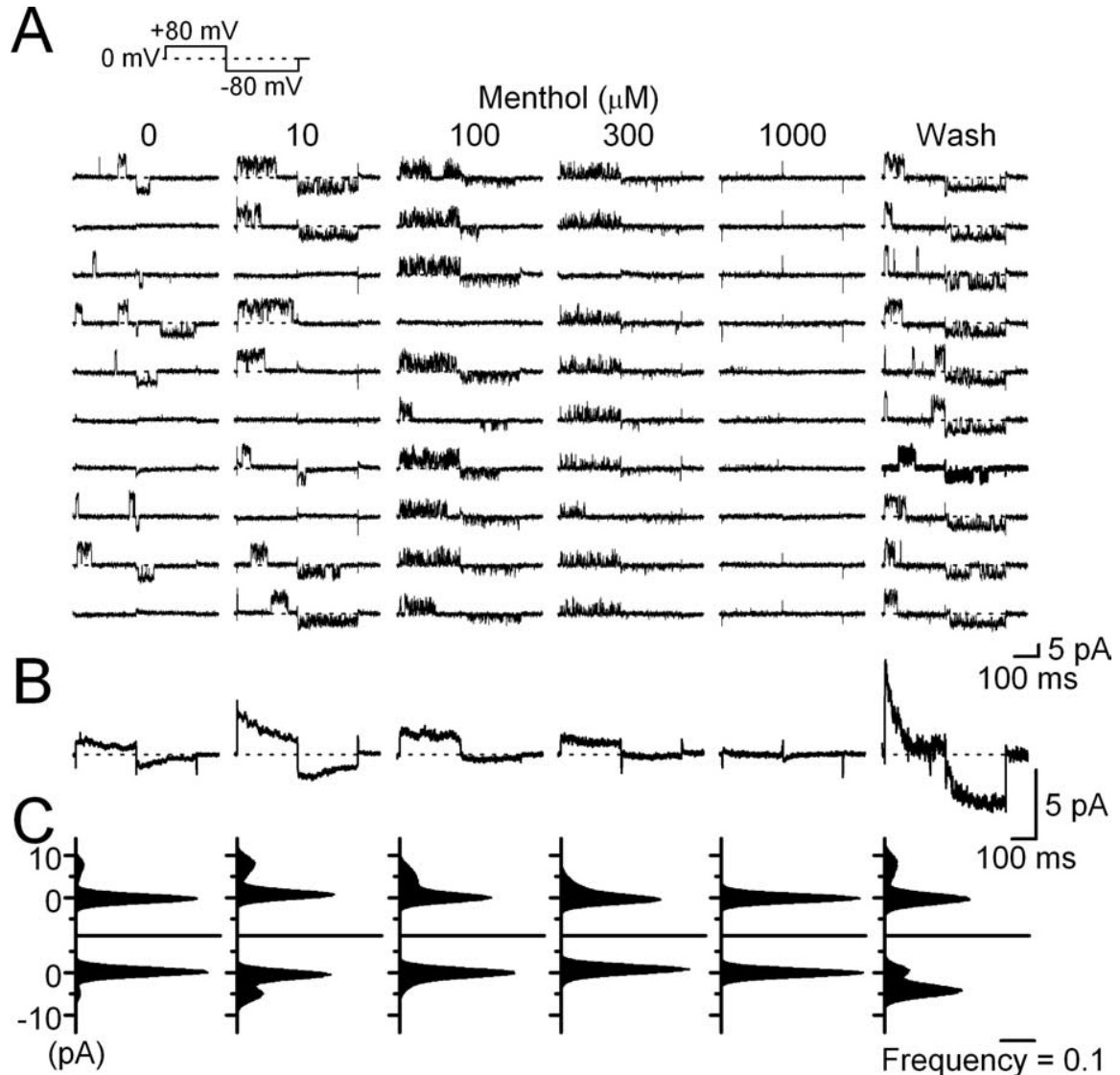

Figure 4. Modulation of TRPA1 single-channel properties by menthol. $A$, Representative cell-attached patch-clamp recordings using a step protocol (top) and different concentrations of menthol. Before washout, $1000 \mu \mathrm{m}$ menthol was used. $\boldsymbol{B}$, Corresponding ensemble average currents from 30 to 80 single traces recorded. C, Corresponding all-point amplitude histograms at +80 and $-80 \mathrm{mV}$.

subset of MO-insensitive neurons only 6.4\% (14 of 218) responded to $30 \mu \mathrm{M}$ menthol (Fig. 6C). Moreover, when using menthol at a concentration as low as $3 \mu \mathrm{M}, 2$ of 46 cells showed a calcium response, both of which also responded to MO. Thus, at low micromolar concentrations the majority $(\sim 70 \%)$ of menthol-sensitive cells belong to the subset of $\mathrm{MO}$-sensitive neurons. These findings suggest that in vivo TRPA1 might contribute to the neuronal sensitivity to menthol, together with TRPM8.

Menthol concentrations $>30 \mu \mathrm{M}$ did not cause an additional increase in the responses of $\mathrm{MO}$-sensitive neurons. The number of responsive cells decreased slightly, from $38.1 \%$ at $30 \mu \mathrm{M}$ to $34 \%$ at $300 \mu \mathrm{M}$, and the amplitude of the $\mathrm{Ca}^{2+}$ response remained virtually unchanged (Fig. $6 C, E$ ). In contrast, the percentage of menthol-sensitive cells within the subset of MO-insensitive neurons increased significantly from $6.4 \%$ at $30 \mu \mathrm{M}$ to $18.5 \%$ at $300 \mu \mathrm{M}$ (Fig. 6C). These results are consistent with the notion that these cells express TRPM8, which is only half-maximally activated at $30 \mu \mathrm{M}$ menthol. Intriguingly, in the MO-sensitive subset of cells we observed a striking increase in the number of responsive cells (79\%) after application of menthol at $1 \mathrm{~mm}$ (Fig. 6C). This is in strong contradiction with the virtually complete inhibition of TRPA1 currents in CHO cells by $1 \mathrm{~mm}$ menthol (Figs. 2, 3 ). Given that millimolar concentrations of menthol can induce $\mathrm{Ca}^{2+}$ release from intracellular stores in different cell types (Mahieu et al., 2007), we tested the effects of $1 \mathrm{~mm}$ menthol on sensory neurons in the absence of extracellular calcium. Using this protocol, we measured $\mathrm{Ca}^{2+}$ influx-independent menthol responses in a number of both $\mathrm{MO}$ sensitive and MO-insensitive cells (see supplemental Fig. S2, available at www. jneurosci.org as supplemental material), indicating that $1 \mathrm{~mm}$ menthol can lead to $\mathrm{Ca}^{2+}$ release from intracellular calcium stores in sensory neurons.

Interestingly, we observed characteristic differences in the kinetics of responses to low $(30 \mu \mathrm{M})$ and high $(1 \mathrm{mM})$ concentrations of menthol. Especially at high concentrations of menthol, we often observed a transient increase in $\left[\mathrm{Ca}^{2+}\right]_{\mathrm{i}}$ after washout of menthol (Fig. 6D, arrow), highly reminiscent of our observations in TRPA1-expressing CHO cells (Figs. 1, 3). Such a rebound effect of menthol was never observed in MO-insensitive cells or in HEK cells heterologously expressing TRPM8 (data not shown). Together, these results strongly indicate that menthol acts at two separate ionotropic menthol receptors in distinct subsets of primary sensory neurons, probably TRPM8 and TRPA1.

\section{The number of menthol-sensitive neurons is reduced in TRPA1-deficient mice}

To further address the question of whether TRPA1 mediates menthol-induced calcium transients in sensory neurons, we used trigeminal ganglion cells from TRPA1 knock-out mice. We found that $<1 \%$ ( 2 of 267 ) of sensory neurons from TRPA1-deficient animals were activated in calcium imaging measurements by 100 $\mu \mathrm{M}$ MO (Fig. $7 B$ ), indicating that MO provides a useful tool for reliable identification of TRPA1 expression in trigeminal neurons. A former study identified a fraction of DRG neurons from TRPA1-null mice that could be stimulated by $10 \mu \mathrm{M}$ MO (Kwan et al., 2006). The discrepancy between both studies might be attributable to different cell types (DRG vs TG neurons) or different cell culture conditions (NGF and GDNF vs no neurotrophic factors).

In our study, 26\% (34 of 131) of all WT-derived neurons showed an increase of intracellular calcium in response to application of $100 \mu \mathrm{M}(-)$-menthol, 71\% (24 of 34) of which also responded to $100 \mu \mathrm{M} \mathrm{MO}$. Interestingly, the number of mentholsensing neurons was significantly reduced to $9 \%$ in TRPA1deficient mice (Fig. $7 B$ ), indicating that indeed, TRPA1 contributes to the menthol sensitivity of sensory neurons in primary cell culture. In contrast, the relative number of neurons that showed sensitivity to the TRPV1-specific agonist capsaicin were the same in WT and TRPA1 knock-out-derived cell cultures [WT, 37\% (49 of 131 ); $\mathrm{KO}, 38 \%$ (56 of 149)].

Moreover, we observed characteristic differences in the kinetics of menthol responses between $\mathrm{MO}$-sensitive and $\mathrm{MO}$ insensitive neurons (Fig. 7C). The decrease of $\left[\mathrm{Ca}^{2+}\right]_{\mathrm{i}}$ after washout of menthol in MO-sensitive neurons was relatively slow, requiring several minutes for a full recovery of the initial basal $\left[\mathrm{Ca}^{2+}\right]_{\mathrm{i}}$ level. Washout of the menthol effect in TRPA1expressing $\mathrm{CHO}$ cells was similarly slow (Fig. 1). In contrast, in MO-insensitive cells the intracellular $\mathrm{Ca}^{2+}$ concentration re- 


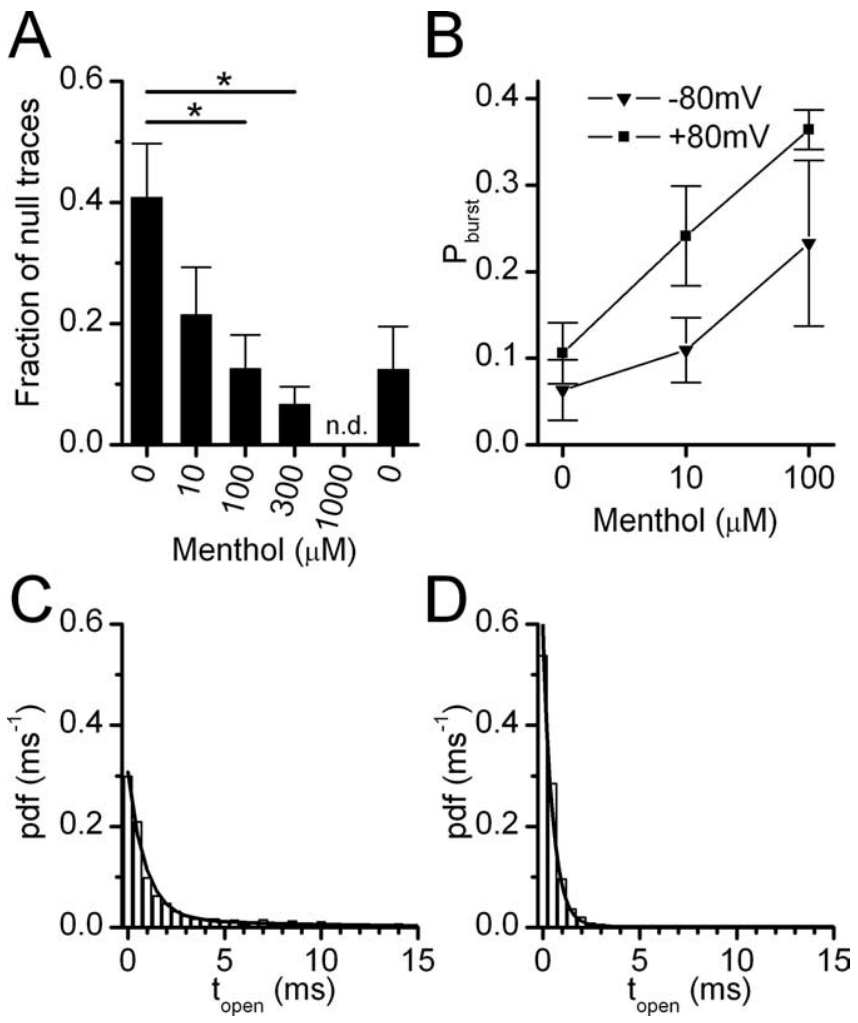

Figure 5. Kinetics of TRPA1 single channels in dependence of the menthol concentration. $\boldsymbol{A}$, Dose dependence of the effect of menthol on the fraction of null traces in cell-attached patchclamp recording, using the step protocol indicated in Figure 4. n.d., No data. $\boldsymbol{B}$, Dose dependence of the effect of menthol on the TRPA1 burst probability at +80 and $-80 \mathrm{mV}(n=5)$. $\boldsymbol{C}$, $D$, Representative example of probability density function ( $\mathrm{pdf}$ ) of open channel dwell time $\left(t_{\text {open }}\right)$ at $+80 \mathrm{mV}$ in the absence $(\boldsymbol{C})$ and presence $(\boldsymbol{D})$ of $100 \mu \mathrm{m}$ menthol. Black lines represent a biexponential $(\boldsymbol{C})$ and monoexponential $(\boldsymbol{D})$ fit to the data. Error bars indicate $S E M .{ }^{*} p<0.05$; $n=3-5$.

turned faster after washout of menthol, in line with the virtually immediate reversal of the effect of menthol on TRPM8. To determine the kinetics of this calcium decay, we calculated the time for calcium transients to decline to $60 \%$ of the peak amplitude after the onset of a $30 \mathrm{~s}$ menthol pulse. Whereas cells that were not responding to $\mathrm{MO}$ showed a fast decay $(40 \pm 1 \mathrm{~s} ; n=7)$, calcium signals decreased significantly $(p<0.05)$ slower in $\mathrm{MO}$-sensitive neurons (98 $\pm 20 \mathrm{~s} ; n=6$ ) (Fig. 7D). Strikingly, mentholinduced calcium transients in neurons from TRPA1-null mice showed exclusively the fast type of decay ( $42 \pm 4 \mathrm{~s} ; n=14$ ) (Fig. $7 C, D)$. These findings give further indication for two molecular menthol receptors in sensory neurons and suggest that TRPA1 mediates the slow calcium decay after menthol stimulation, whereas the fast type probably results from TRPM8 activation.

\section{Cross-modulatory effect of menthol and MO on TRPA1}

Finally we analyzed the effect of menthol on MO-induced TRPA1 activation. In line with a previous report (Macpherson et al., 2006), $100 \mu \mathrm{M}$ menthol completely inhibited MO-activated currents in TRPA1-expressing CHO cells (Fig. 8A,B). Accordingly, trigeminal neurons revealed a decrease of $\mathrm{MO}$-induced calcium transients after application of $1 \mathrm{~mm}$ menthol (Fig. 8C). Currents in $\mathrm{CHO}$ cells and calcium transients in neurons rapidly recovered from inhibition after removal of menthol (Fig. $8 \mathrm{~A}, \mathrm{C}$ ). Interestingly, in TRPA1-expressing CHO cells, prestimulation with 100 $\mu \mathrm{M}$ menthol had no significant effect on the amplitude of $\mathrm{MO}$ induced inward currents at $-80 \mathrm{mV}[-150 \pm 17.4 \mathrm{pA} / \mathrm{pF}(n=3)$ vs $-157 \pm 20.5 \mathrm{pA} / \mathrm{pF}(n=17)$ without menthol prestimulation]. Note that $\mathrm{MO}(20 \mu \mathrm{M})$-induced inward currents were significantly larger than menthol $(100 \mu \mathrm{M})$-activated currents (menthol, $-34 \pm 1.5 ; \mathrm{MO},-150 \pm 17.4 \mathrm{pA} / \mathrm{pF}$ at $-80 \mathrm{mV} ; p<$ $0.01 ; n=3)$, suggesting that $\mathrm{MO}$ induces a more pronounced depolarization of TRPA1-expressing cells than menthol (Fig. $8 D, E)$. Because receptor-mediated depolarization influences the determination of calcium entry in sensory neurons, the significantly lower potency of menthol for activating inward TRPA1 currents may also explain why in calcium imaging experiments only a fraction of $\mathrm{MO}$-sensitive neurons showed a discernible response to $100 \mu \mathrm{M}$ menthol. Therefore, and because of its effect on TRPM8, menthol alone will not be a good compound for identifying TRPA1-expressing neurons in calcium imaging experiments. Surprisingly, menthol was no longer able to activate TRPA1 currents when applied after stimulation with MO (Fig. $8 \mathrm{D}$ and data not shown). Likewise, the response to $30 \mu \mathrm{M}$ menthol was abolished in all MO-sensitive neurons ( 0 of 13) after prestimulation with MO (Fig. $8 F$ ). Together, these data indicate that the stimulatory effect of menthol on TRPA1 is absent during or after stimulation with MO, whereas the blocking effect remains unaffected.

\section{Discussion}

Menthol, a natural alcohol found in mint leaves and many essential oils (e.g., peppermint oil), is broadly used in balms, liniments, and troches with medical implementation for alleviation of pain and irritation of skin and airways. These products exploit the soothing effects of the cooling agent menthol; however, by itself menthol can also produce a burning pain. The cellular mechanisms underlying the ambivalent perception and psychophysical effects of menthol are still poorly understood. Most recent studies focus on the cold-activated TRPM8 as the prime molecular target for menthol in sensory neurons. However, activation of TRPM8 could not explain the algesic effects of menthol, given that the channel is not expressed in nociceptive primary sensory neurons. The presence of cold/menthol-sensitive neurons in vitro that do not have any detectable TRPM8 mRNA (Nealen et al., 2003) substantiate the hypothesis of various molecular receptors for menthol, and very recently, two independent groups could demonstrate that TRPM8-lacking mice still exhibit a considerable amount of menthol-sensing DRG and trigeminal neurons (Colburn et al., 2007; Dhaka et al., 2007).

TRPA1 expression is restricted to a distinct subpopulation of nociceptive neurons from trigeminal and dorsal root ganglia that show very little or no expression of TRPM8 (Story et al., 2003; Kobayashi et al., 2005). Activation of TRPA1 produces acute pain and neurogenic inflammation through peripheral release of neuropeptides (substance $\mathrm{P}$ and CGRP), purines, and other transmitters from activated nerve endings. This, in turn, produces robust hypersensitivity to thermal and mechanical stimuli. Previous studies had shown that menthol at high micromolar concentrations $(\geq 250 \mu \mathrm{M})$ did not activate TRPA1 and even exerts an antagonistic effect on activation of the channel by cold, cinnamaldehyde, and the cysteine reagent MTSEA. Surprisingly, we found that menthol has a clear bimodal effect on TRPA1, acting as a potent agonist at submicromolar to low micromolar concentrations and as an antagonist at higher concentrations. This bimodal effect was observed for four different menthol stereoisomers as well as for the structurally related compound thymol.

Both whole-cell and single-channel recordings of heterologously expressed TRPA1 showed two distinct effects of menthol on the channel, which together can explain its bell-shaped dose- 
A
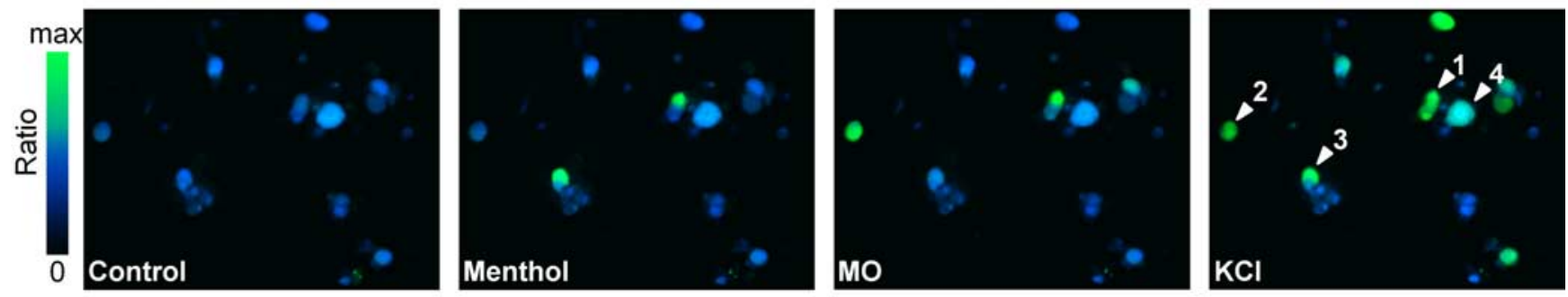
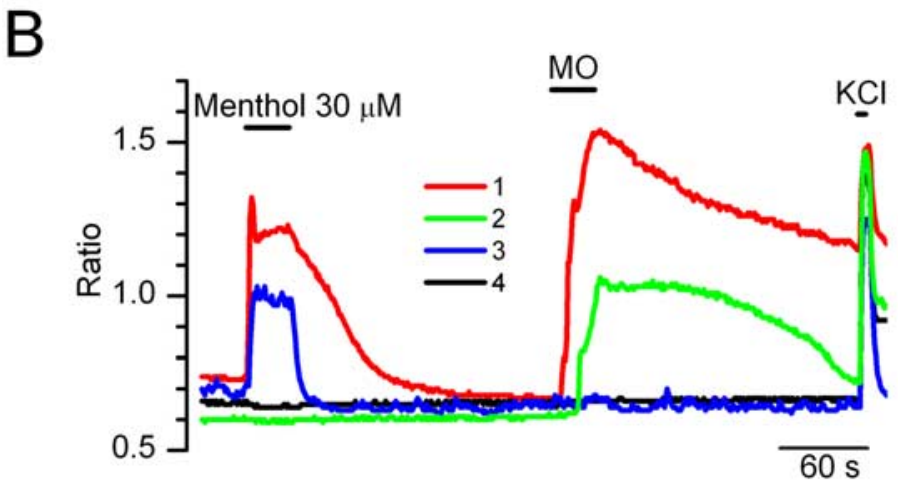

D

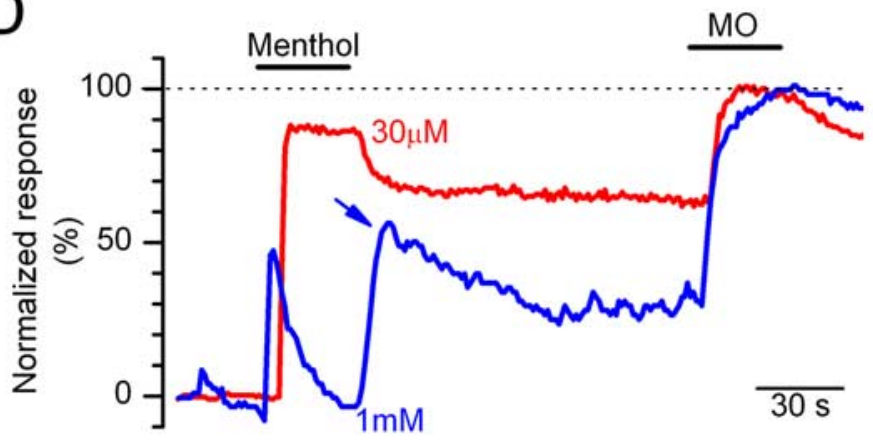

C
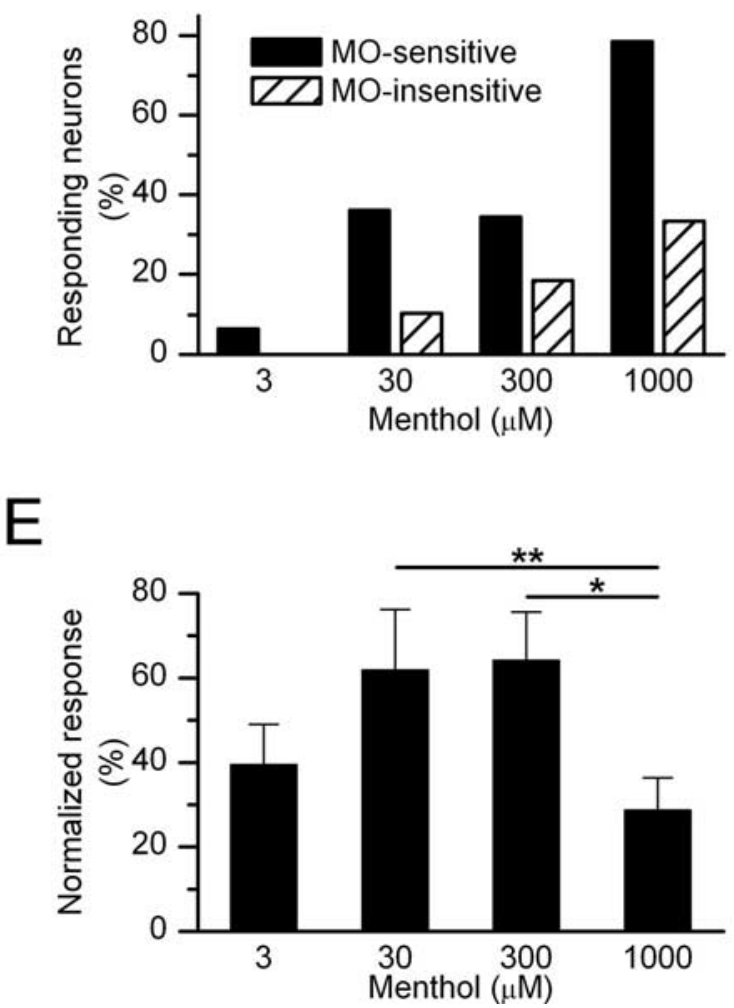

Figure 6. Menthol responses in mouse trigeminal neurons. $A$, Ratiometric images of fura- $2 \mathrm{AM}$-loaded neurons in control conditions and during application of $30 \mu \mathrm{m}$ menthol, $100 \mu \mathrm{M}$ M0, or 45 $\mathrm{mm} \mathrm{KCl} . \boldsymbol{B}$, Individual $\left[\mathrm{Ca}^{2+}\right]_{\mathrm{i}}$ traces from the neurons indicated in $\boldsymbol{A}$. $\boldsymbol{C}$, Percentages of M0-sensitive and $\mathrm{M} 0$-insensitive neurons that responded to different menthol concentrations. $\boldsymbol{D}$, Exemplary traces of $\mathrm{MO}$-sensitive cell responses to stimulation with $30 \mu \mathrm{m}$ and $1 \mathrm{~mm}$ menthol normalized to the $\mathrm{M} 0$ amplitude. Arrow indicates the "off response." $\boldsymbol{E}$, Mean maximal amplitudes of menthol responses in $\mathrm{M} 0$-sensitive cells normalized to the $\mathrm{MO}$ amplitude. Error bars indicate SEM. ${ }^{*} p<0.05{ }^{* *} p<0.01$.

response curve. At the whole-cell level, menthol induces a leftward shift of the TRPA1 activation curve, similar to its effect on TRPM8 (Voets et al., 2004, 2007). This shift results in a marked increase of the probability of channel opening at physiological voltages. In addition, menthol dose-dependently reduces the maximal whole-cell conductance, leading to an overall inhibition of TRPA1 current at higher concentrations. At the single-channel level, we measured constitutive TRPA1 activity in the absence of menthol, characterized by periods of burst-like channel activity interspaced by long closing between bursts. Menthol significantly increased the burst probability, by prolonging the burst durations and shortening the closed time between bursts. Additionally, menthol induces a rapid flickering block, as evidenced by the sharp decrease in the open time within bursts.

Based on these data, we hypothesize a model whereby TRPA1 has two distinct interaction sites for menthol. Menthol binding to the activating site influences channel gating, causing a shift of the voltage dependence (whole cell) and an increased burst probabil- ity ( single channel). Menthol binding to the inactivating site provokes rapid channel block, as evidenced by the overall reduction in whole-cell conductance and the flickering behavior of single TRPA1 channels. The kinetics of the menthol-induced channel block are consistent with a direct action at the channel pore, although an allosteric effect cannot be excluded at this point. Clearly, additional mutagenesis and structural analyses will be required to delineate the exact interaction sites of menthol on TRPA1.

Two recent reports have provided compelling evidence that activation of TRPA1 by several agonists occurs through covalent modification of N-terminal cysteine residues on the channel (Hinman et al., 2006; Macpherson et al., 2007). In particular, covalent modification of TRPA1 occurs with agonists such as $\mathrm{MO}$, cinnamaldehyde, and acrolein, which are electrophiles that can readily react with the thiol group of cysteine residues. It is, however, unlikely that the dual effect of menthol on TRPA1 involves covalent binding, given the low reactivity of menthol and 
the rapid reversibility of the effects of menthol on the channel. Similarly, activation of TRPA1 by icilin was shown to be independent of covalent cysteine modification (Macpherson et al., 2007). Interestingly, during or after MO application, $100 \mu \mathrm{M}$ menthol could not activate TRPA1, whereas the blocking effect persisted. These data indicate that covalent modification of TRPA1 specifically affects the effect of menthol on channel gating.

Among menthol isomers, (-)menthol is the one that occurs most widely in nature (Eccles, 1994). It would be reasonable that TRPA1, as a sensor of naturally occurring compounds, is modulated by $(-)$-menthol most potently. (-)-Menthyl chloride, which lacks the alcohol group, also activated TRPA1, indicating that the alcohol group is not a prerequisite for its activation. However, considering that the effect of (-)menthyl chloride stayed long after washout whereas menthol showed fast desensitization, the alcohol group might have some effect on the interaction between drugs and the channel. Moreover, thymol, a major constituent of thyme, which has a chemical structure similar to menthol, also showed bimodal action on TRPA1 and strikingly produced more profound inward currents than menthol, suggesting involvement of different kinetics of channel modulation.

In previous studies on sensory neurons from trigeminal or dorsal root ganglia, menthol sensitivity was often taken as evidence for expression of TRPM8, whereas TRPA1-expressing cells were identified based on sensitivity to MO or cinnamaldehyde. This approach has led to conflicting results concerning the expression pattern of these channels. Indeed, in situ hybridization and immunostaining indicated that TRPM8 and TRPA1 expression is mutually exclusive, whereas functional studies revealed menthol responses in a significant (but highly variable) fraction of $\mathrm{MO}$ - or cinnamaldehyde-sensitive neurons (Babes et al., 2004; Jordt et al., 2004). In the present study, we used sensitivity to $\mathrm{MO}$ at $100 \mu \mathrm{M}$ to discriminate between TRPA1-expressing and TRPA1-negative trigeminal neurons in WT mice. We could confirm the specificity of MO for

TRPA1 in our experiments showing that trigeminal neurons from TRPA $1^{-1-}$ mice lack a response to $100 \mu \mathrm{M}$ MO. Importantly, we found that a large proportion of the mentholsensitive WT cells belonged to the MO-sensitive (TRPA1expressing) subpopulation, particularly at low micromolar menthol concentrations. Moreover, in TRPA1 ${ }^{-1-}$ animals, the number of menthol-sensitive neurons was significantly
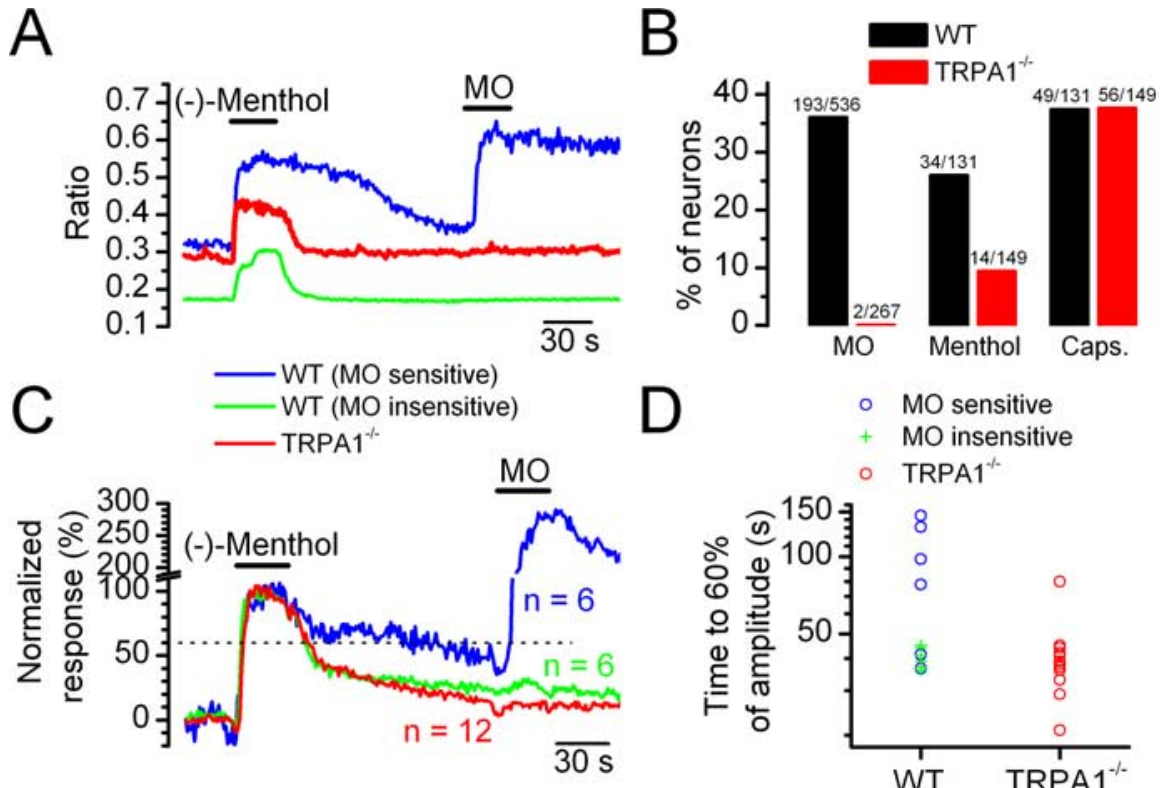

Figure 7. Menthol responses in mouse trigeminal neurons. $A$, Individual $\left[\mathrm{Ca}^{2+}\right]_{i}$ traces from single neurons derived from wild-type animals and TRPA1 knock-out mice. $\boldsymbol{B}$, Percentages of neurons from WT and TRPA1 knock-out animals that responded to different stimuli, including $100 \mu \mathrm{m}$ M0, $100 \mu \mathrm{m}$ menthol, and $1 \mu \mathrm{m}$ capsaicin (Caps.). C, Comparison of the time course of the response to $100 \mu \mathrm{m}$ menthol in $\mathrm{M} 0$-sensitive and $\mathrm{M} 0$-insensitive cells from wild-type and TRPA $1^{-/-}$mice. $\boldsymbol{D}$, The time for the calcium signal to decline to $60 \%$ of the maximal menthol response.
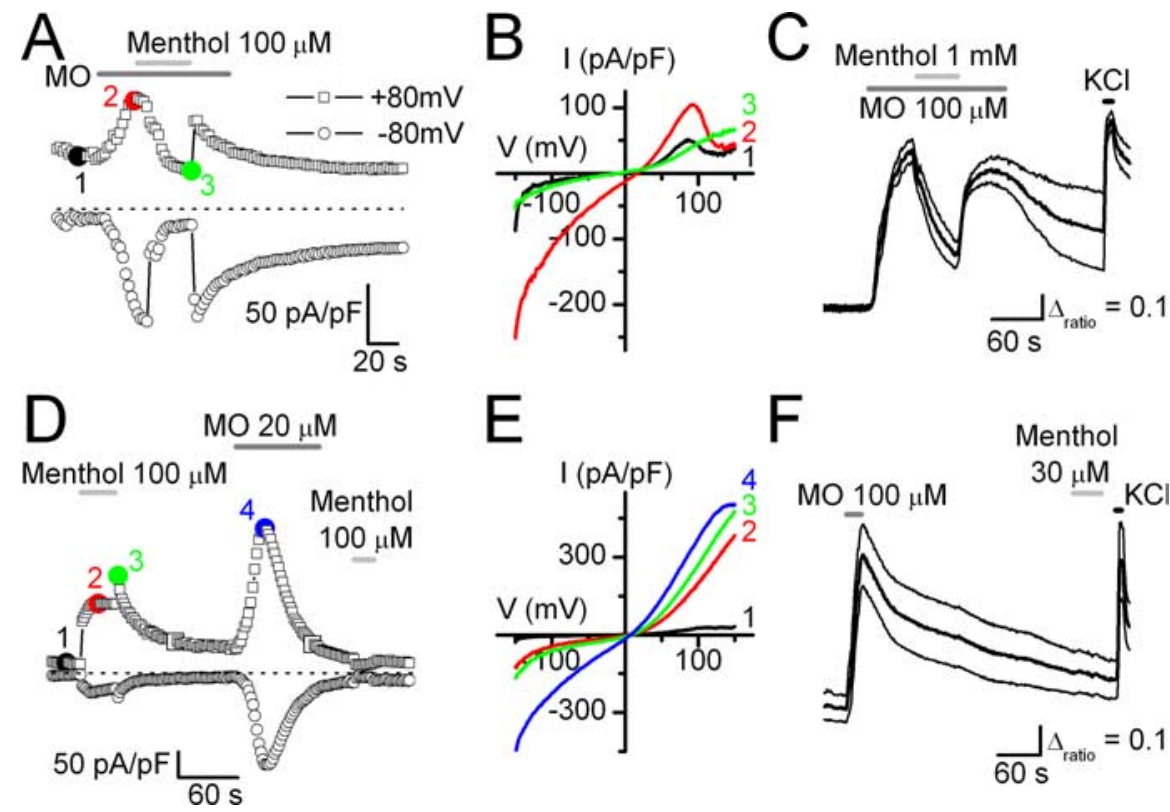

Figure 8. Cross-modulatory effect of menthol and M0 on TRPA1. $\boldsymbol{A}$, Cross-desensitizing effect of $100 \mu \mathrm{m}$ menthol on MOactivated current. $\boldsymbol{B}, \mathrm{I}-V$ relationships obtained at the times indicated in $\boldsymbol{A}$. $\boldsymbol{C}$, Inhibition of $\mathrm{M} 0$-stimulated trigeminal neurons by $1 \mathrm{~mm}$ menthol in calcium imaging measurements (thick line, mean values; thin lines, SEM; $n=4$ ). $\boldsymbol{D}$, Representative time course of serial application of menthol and M0. Note the opposite effects of $100 \mu \mathrm{m}$ menthol before and after M0 application. $\boldsymbol{E}, I-V$ relationships obtained at the times indicated in $\boldsymbol{D}$. F, Prior application of $100 \mu \mathrm{M} M 0$ prevents responses of trigeminal neurons to $30 \mu \mathrm{m}$ menthol (thick line, mean values; thin lines, SEM; $n=11$ ).

reduced, similar to the reduction in menthol sensitivity reported in TRPM $8^{-/-}$mice (Colburn et al., 2007; Dhaka et al., 2007). From this we conclude that not only TRPM8 but also TRPA1 can act as a sensitive menthol receptor in trigeminal neurons, which may explain many of the above-mentioned paradoxes.

Our experiments revealed several characteristic finger- 
prints of mode of menthol action on TRPA1 that could be used to discriminate between TRPM8- and TRPA1-mediated menthol responses in sensory neurons. First, we observed that TRPA1 currents in CHO cells decayed slowly $(\tau>20 \mathrm{~s})$ after washout of menthol, which contrasts to the virtually immediate reversal of the effect of menthol on TRPM8 $(\tau<2 \mathrm{~s})$ (Voets et al., 2007). Accordingly, in trigeminal neurons we observed clear differences in the time course of the $\mathrm{Ca}^{2+}$ signal after washout of menthol: in WT neurons, MO-sensitive cells displayed a systematically slower decay phase than MOinsensitive cells. Moreover, the $\mathrm{Ca}^{2+}$ signal in neurons from TRPA1 ${ }^{-\prime-}$ mice always decayed rapidly after menthol washout. Second, maximal inward TRPA1 currents in $\mathrm{CHO}$ cells were obtained at a menthol concentration of $\sim 100 \mu \mathrm{M}$, and higher concentrations led to lower responses or even complete channel block. Accordingly, menthol responses in MOsensitive neurons were maximal at $100-300 \mu \mathrm{M}$ and significantly reduced at higher concentrations. In contrast, in MOinsensitive neurons or TRPM8-expressing HEK cells we found no indications for inhibition of menthol responses at higher menthol concentrations. Third, both in TRPA1-expressing $\mathrm{CHO}$ cells and in MO-sensitive neurons we observed a pronounced rebound effect after washout of high menthol concentrations. A likely explanation of the transient increase in TRPA1 activity after washout is that reversal of the channelblocking effect occurs more rapidly than the reversal of the activating effect. Importantly, we never observed such a rebound phenomenon in MO-insensitive neurons or cells heterologously expressing TRPM8. Together, our results demonstrate that TRPM8 and TRPA1 are two separate menthol sensors with distinct functional properties. Moreover, our findings are fully in line with the notion that these channels mark two different subsets of sensory neurons that exhibit little or no overlap (Story et al., 2003; Kobayashi et al., 2005).

TRPA1-deficient mice exhibit pronounced defects in sensing environmental irritants such as acrolein and inflammatory mediators such as bradykinin and anandamide, highlighting the potential importance of TRPA 1 as a target for treatment of different forms of pain. Our present results provide important new information on the contribution of TRPA1 to the ambivalent sensory effects of menthol, a widely used additive in counterirritants, analgesics, toothpaste and cosmetic products. The bimodal action of menthol on TRPA1 challenges our current view of somatosensory principles for mammalian temperature and menthol sensation and sheds new light on the underlying molecular processes.

\section{References}

Abe J, Hosokawa H, Okazawa M, Kandachi M, Sawada Y, Yamanaka K, Matsumura K, Kobayashi S (2005) TRPM8 protein localization in trigeminal ganglion and taste papillae. Brain Res Mol Brain Res 136:91-98.

Babes A, Zorzon D, Reid G (2004) Two populations of cold-sensitive neurons in rat dorsal root ganglia and their modulation by nerve growth factor. Eur J Neurosci 20:2276-2282.

Bandell M, Story GM, Hwang SW, Viswanath V, Eid SR, Petrus MJ, Earley TJ, Patapoutian A (2004) Noxious cold ion channel TRPA1 is activated by pungent compounds and bradykinin. Neuron 41:849-857.

Bautista DM, Movahed P, Hinman A, Axelsson HE, Sterner O, Hogestatt ED, Julius D, Jordt SE, Zygmunt PM (2005) Pungent products from garlic activate the sensory ion channel TRPAl. Proc Natl Acad Sci USA 102:12248-12252.

Bautista DM, Jordt SE, Nikai T, Tsuruda PR, Read AJ, Poblete J, Yamoah EN, Basbaum AI, Julius D (2006) TRPAl mediates the inflammatory actions of environmental irritants and proalgesic agents. Cell 124:1269-1282.
Cliff MA, Green BG (1994) Sensory irritation and coolness produced by menthol: evidence for selective desensitization of irritation. Physiol Behav 56:1021-1029.

Colburn RW, Lubin ML, Stone Jr DJ, Wang Y, Lawrence D, D'Andrea MR, Brandt MR, Liu Y, Flores CM, Qin N (2007) Attenuated cold sensitivity in TRPM8 null mice. Neuron 54:379-386.

Damann N, Rothermel M, Klupp BG, Mettenleiter TC, Hatt H, Wetzel CH (2006) Chemosensory properties of murine nasal and cutaneous trigeminal neurons identified by viral tracing. BMC Neurosci 7:46.

Dhaka A, Murray AN, Mathur J, Earley TJ, Petrus MJ, Patapoutian A (2007) TRPM8 is required for cold sensation in mice. Neuron 54:371-378.

Doerner JF, Gisselmann G, Hatt H, Wetzel CH (2007) Transient receptor potential channel A1 is directly gated by calcium ions. J Biol Chem 282:13180-13189.

Eccles R (1994) Menthol and related cooling compounds. J Pharm Pharmacol 46:618-630.

Galeotti N, Di Cesare ML, Mazzanti G, Bartolini A, Ghelardini C (2002) Menthol: a natural analgesic compound. Neurosci Lett 322:145-148.

Green BG (1992) The sensory effects of l-menthol on human skin. Somatosens Mot Res 9:235-244.

Green BG, McAuliffe BL (2000) Menthol desensitization of capsaicin irritation. Evidence of a short-term anti-nociceptive effect. Physiol Behav 68:631-639.

Hill K, Schaefer M (2007) TRPAl is differentially modulated by the amphipathic molecules trinitrophenol and chlorpromazine. J Biol Chem 282:7145-7153.

Hinman A, Chuang HH, Bautista DM, Julius D (2006) TRP channel activation by reversible covalent modification. Proc Natl Acad Sci USA 103:19564-19568.

Jordt SE, Bautista DM, Chuang HH, McKemy DD, Zygmunt PM, Hogestatt ED, Meng ID, Julius D (2004) Mustard oils and cannabinoids excite sensory nerve fibres through the TRP channel ANKTM1. Nature 427:260-265.

Kobayashi K, Fukuoka T, Obata K, Yamanaka H, Dai Y, Tokunaga A, Noguchi K (2005) Distinct expression of TRPM8, TRPA1, and TRPV1 mRNAs in rat primary afferent neurons with adelta/c-fibers and colocalization with trk receptors. J Comp Neurol 493:596-606.

Kwan KY, Allchorne AJ, Vollrath MA, Christensen AP, Zhang DS, Woolf CJ, Corey DP (2006) TRPAl contributes to cold, mechanical, and chemical nociception but is not essential for hair-cell transduction. Neuron 50:277-289.

Macpherson LJ, Hwang SW, Miyamoto T, Dubin AE, Patapoutian A, Story GM (2006) More than cool: promiscuous relationships of menthol and other sensory compounds. Mol Cell Neurosci 32:335-343.

Macpherson LJ, Dubin AE, Evans MJ, Marr F, Schultz PG, Cravatt BF, Patapoutian A (2007) Noxious compounds activate TRPA1 ion channels through covalent modification of cysteines. Nature 445:541-545.

Mahieu F, Owsianik G, Verbert L, Janssens A, De Smedt H, Nilius B, Voets T (2007) TRPM8-independent menthol-induced $\mathrm{Ca}^{2+}$ release from endoplasmic reticulum and golgi. J Biol Chem 282:3325-3336.

McKemy DD, Neuhausser WM, Julius D (2002) Identification of a cold receptor reveals a general role for TRP channels in thermosensation. Nature 416:52-58.

Nagata K, Duggan A, Kumar G, Garcia-Anoveros J (2005) Nociceptor and hair cell transducer properties of TRPA1, a channel for pain and hearing. J Neurosci 25:4052-4061.

Namer B, Seifert F, Handwerker HO, Maihofner C (2005) TRPAl and TRPM8 activation in humans: effects of cinnamaldehyde and menthol. NeuroReport 16:955-959.

Nealen ML, Gold MS, Thut PD, Caterina MJ (2003) TRPM8 mRNA is expressed in a subset of cold-responsive trigeminal neurons from rat. J Neurophysiol 90:515-520.

Nilius B, Talavera K, Owsianik G, Prenen J, Droogmans G, Voets T (2005) Gating of TRP channels: a voltage connection? J Physiol (Lond) 567:35-44.

Obata K, Katsura H, Mizushima T, Yamanaka H, Kobayashi K, Dai Y, Fukuoka T, Tokunaga A, Tominaga M, Noguchi K (2005) TRPAl induced in sensory neurons contributes to cold hyperalgesia after inflammation and nerve injury. J Clin Invest 115:2393-2401.

Patapoutian A, Peier AM, Story GM, Viswanath V (2003) ThermoTRP channels and beyond: mechanisms of temperature sensation. Nat Rev Neurosci 4:529-539. 
Peier AM, Moqrich A, Hergarden AC, Reeve AJ, Andersson DA, Story GM, Earley TJ, Dragoni I, McIntyre P, Bevan S, Patapoutian A (2002) A TRP channel that senses cold stimuli and menthol. Cell 108:705-715.

Story GM, Peier AM, Reeve AJ, Eid SR, Mosbacher J, Hricik TR, Earley TJ, Hergarden AC, Andersson DA, Hwang SW, McIntyre P, Jegla T, Bevan S, Patapoutian A (2003) ANKTM1, a TRP-like channel expressed in nociceptive neurons, is activated by cold temperatures. Cell 112:819-829.

Thut PD, Wrigley D, Gold MS (2003) Cold transduction in rat trigeminal ganglia neurons in vitro. Neuroscience 119:1071-1083.

Voets T, Droogmans G, Wissenbach U, Janssens A, Flockerzi V, Nilius B (2004) The principle of temperature-dependent gating in cold- and heatsensitive TRP channels. Nature 430:748-754.

Voets T, Owsianik G, Janssens A, Talavera K, Nilius B (2007) TRPM8 volt- age sensor mutants reveal a mechanism for integrating thermal and chemical stimuli. Nat Chem Biol 3:174-182.

Vogt-Eisele AK, Weber K, Sherkheli MA, Vielhaber G, Panten J, Gisselmann G, Hatt H (2007) Monoterpenoid agonists of TRPV3. Br J Pharmacol 151:530-540.

Winston J, Toma H, Shenoy M, Pasricha PJ (2001) Nerve growth factor regulates VR-1 mRNA levels in cultures of adult dorsal root ganglion neurons. Pain 89:181-186.

Xu H, Delling M, Jun JC, Clapham DE (2006) Oregano, thyme and clovederived flavors and skin sensitizers activate specific TRP channels. Nat Neurosci 9:628-635.

Zurborg S, Yurgionas B, Jira JA, Caspani O, Heppenstall PA (2007) Direct activation of the ion channel TRPA1 by $\mathrm{Ca}^{2+}$. Nat Neurosci 10:277-279. 